\title{
Numerical investigation of the effect of swirl flow in-homogeneity and stability on diesel engine combustion and emissions
}

International I of Engine Research I3(5) 482-496

(C) RWTH Aachen University 2012 Reprints and permissions: sagepub.co.uk/journalsPermissions.nav DOI: $10.1177 / 146808741243783$ | jer.sagepub.com BSAGE

\author{
Reza Rezaei', Stefan Pischinger', Jens Ewald ${ }^{2}$ and Philipp Adomeit ${ }^{2}$
}

\begin{abstract}
The present study is aimed at numerically investigating the effect of in-cylinder charge motion on mixture preparation, combustion and emission formation in a high-speed direct-injection diesel engine. Previous investigations have shown that different valve-lift strategies nominally lead to similar in-cylinder filling and global swirl levels. However, significant differences in engine-out emissions, especially soot emission, give rise to the assumption that the flow structure and local differences of the swirl motion distribution have a noticeable effect on emission behaviour. In this work, different swirl generation strategies applying different intake valve actuation schemes are numerically investigated by applying transient in-cylinder computational fluid dynamic simulations using both the Reynolds-averaged Navier-Stokes model and the multi-cycle large-eddy simulation approach. Two operating points within the operating range of current diesel passenger cars during federal test procedure 75 and new European driving cycles are simulated. The injection and combustion simulations of different valve strategies show that an in-homogeneity in the in-cylinder flow structure leads to a significant increase in soot emissions, and agree with the observed trends of corresponding experimental investigations.
\end{abstract}

\author{
Keywords \\ Diesel engine, simulation, in-cylinder flow, combustion, emission formation
}

Date received: 7 October 2010; accepted: II October 201I

\section{Introduction}

In order to achieve new emission standards and reduce fuel consumption in future diesel engines, the combustion system requires intense development. In order to simultaneously improve the soot-nitrogen oxide $\left(\mathrm{NO}_{\mathrm{x}}\right)$ trade-off and decrease fuel consumption in comparison to traditional combustion systems, numerous advanced technologies are taken into consideration. These include high-pressure injection equipment using fast-opening piezo-actuated injectors on the one hand and, on the other hand, careful design of the piston bowl in order to reach an optimized distribution of the air-fuel mixture between bowl and squish volume. In addition to these, an optimization of the in-cylinder swirl charge motion is of vital importance. The effects of the incylinder charge motion distribution on combustion and emission behaviour of diesel engines are investigated in this study.

The effects of in-cylinder flow and swirl inhomogeneity have been studied by several investigators. In 1995, Stephenson and Rutland ${ }^{1}$ simulated intake flow and combustion in a heavy-duty directinjection (DI) diesel engine resulting from different intake flow configurations and compared these with the significance of spray-wall interaction effects, using the computational fluid dynamic (CFD) code KIVA-3. Two separate computational grids were applied in KIVA: one for intake flow simulation and one for combustion simulation. At the time directly after intake valve closing (IVC), the data were mapped from the first grid to the combustion grid. Different valve-lift configurations with one and two active valves were simulated. Variations in the in-cylinder flow in terms of turbulent length scales and intensity, as well as their significance to combustion and emissions parameters,

'Institute for Combustion Engines, RWTH Aachen University, Germany ${ }^{2}$ FEV Motorentechnik GmbH, Germany

\section{Corresponding author:}

R Rezaei, Institute for Combustion Engines, RWTH Aachen University, Schinkelstr. 8, 52062 Aachen, Germany.

Email: reza.rezaei@rwth.aachen.de 
were compared with the significance of spray-wall interaction effects. It was concluded that at idling operation, the differences in intake flow were considerably less important than at 3/4 load. Furthermore, it was found that valve deactivation led to higher turbulent kinetic energy and turbulent length scale.

Bianchi et al. ${ }^{2}$ investigated the influence of different initial flow conditions on combustion and emissions in a small-bore high-speed direct-injection (HSDI) diesel engine. The analysis was carried out by applying STAR-CD software for intake stroke simulation and KIVA-II for the compression stroke and combustion simulation. It was concluded that a detailed definition of the initial conditions is required to properly predict the mean and turbulent flow fields at the time of injection near top dead centre (TDC), especially for smallbore HSDI diesel engines.

The injection and combustion simulation using a full cylinder mesh was compared with simulation results considering a sector mesh simulation by Antila et al. ${ }^{3}$ In the case of an HSDI diesel engine, the difference between a sector mesh simulation and a full-cylinder mesh simulation was found to be considerable. The predicted injection velocity was found to have a noteworthy effect on the simulated heat release. ${ }^{3}$

In 2006, Adomeit et al. ${ }^{4}$ showed that an eccentricity in the in-cylinder swirl flow pattern, observed by applying the particle image velocimetry (PIV) measurement technique and intake stroke CFD analysis, can strongly affect the soot oxidation processes. Non-symmetric soot distribution was observed in laser-induced incandescence (LII) measurements at the end of combustion due to an eccentric swirl flow before start of injection.

In 2008 , Ge et al. ${ }^{5}$ modelled the effect of the incylinder flow field on HSDI diesel engine performance and emissions. Two combustion models, KIVACHEMKIN and GAMUT (KIVA-CHEMKIN-G), coupled with a two-step and a multi-step phenomenological soot model were applied. Numerical results were compared with experimental optical diagnostics obtained using laser-induced fluorescence (LIF), LII and PIV. It was concluded that the influence of the offcentred swirl flow on volume-averaged values, including in-cylinder pressure, temperature and heat release rate was negligible. The off-centred swirl flow was found to have higher turbulent kinetic energy and also higher turbulent viscosity. They have observed that an eccentric flow field detected in PIV measurements led to higher amounts of engine soot emissions. It should be noted that in Ge et al. ${ }^{5}$ the intake stroke was not simulated and off-centred swirl flows with an assumed radial velocity distribution were initialized.

Experimental investigations on gas exchange optimization and its impact on emission reduction were presented in previous work. ${ }^{6}$ It was shown that increasing the swirl ratio up to a certain optimum level can improve the engine-out emissions and, simultaneously, the fuel consumption. Furthermore, it was observed that the optimum value of the swirl ratio depends on the operating conditions and engine speed. Therefore, in order to provide the corresponding flexibility, an HSDI diesel engine concept was developed that features a variable intake valve-lift system. In this previous work, the concept of numerically assessing the inhomogeneity of the in-cylinder swirl charge motion was introduced. Very-large-eddy simulation (VLES), a hybrid approach between large-eddy simulation (LES) and Reynolds-averaged Navier-Stokes (RANS) simulation of the in-cylinder flow fields for different valvelift strategies of the same HSDI diesel engine were carried out and correlated to experimentally observed combustion performance. Multi-cycle simulations of the same operating point to cover cyclic instability and CFD simulations of combustion were not carried out at that stage of the research.

In the present study, the work is extended to simulate multi-cycle combustion. Both RANS modelling and the LES multi-cycle approach are employed for intake and compression flow simulations. Different swirl flow patterns are assessed and the numerically predicted emission behaviour, with regards to flow inhomogeneity, is compared to engine measurement results.

\section{Methodology}

\section{Test engine}

The engine simulated in the present work is a state-ofthe-art, small-size class, common-rail 4V HSDI diesel engine with a dual intake port concept with seat swirl chamfers. ${ }^{6}$ The piezo-actuated injector is located vertically at the centre of the fire deck and has a nozzle tip with eight evenly distributed holes. The engine specifications are summarized in Table 1. Detailed descriptions of the experimental setup can be found in Adolph et al. ${ }^{6}$

The gas exchange process is optimized by using an intake port concept consisting of a filling and a tangential port, both with seat swirl chamfers. ${ }^{6}$ One important goal of this port concept is to provide a high volumetric efficiency by an optimized flow coefficient. Figure 1 shows the flow measurements of the port design performed on a steady-state flow test bench.

Table I. Test engine specification data.

\begin{tabular}{ll}
\hline Bore $(\mathrm{mm})$ & 75 \\
Stroke $(\mathrm{mm})$ & 88.3 \\
Squish height $(\mathrm{mm})$ & 0.7 \\
Compression ratio & 15.1 \\
Fuel injection system & Bosch 2000 bar \\
& piezo-actuated \\
No. of nozzle hole & 8 \\
Nozzle hole diameter $(\mu \mathrm{m})$ & 113 \\
Spray angle $\left({ }^{\circ}\right)$ & 153 \\
Intake valve opens $\left({ }^{\circ} \mathrm{CA}\right.$ ATDC) & -355 \\
Engine control & Bosch EDC I6
\end{tabular}




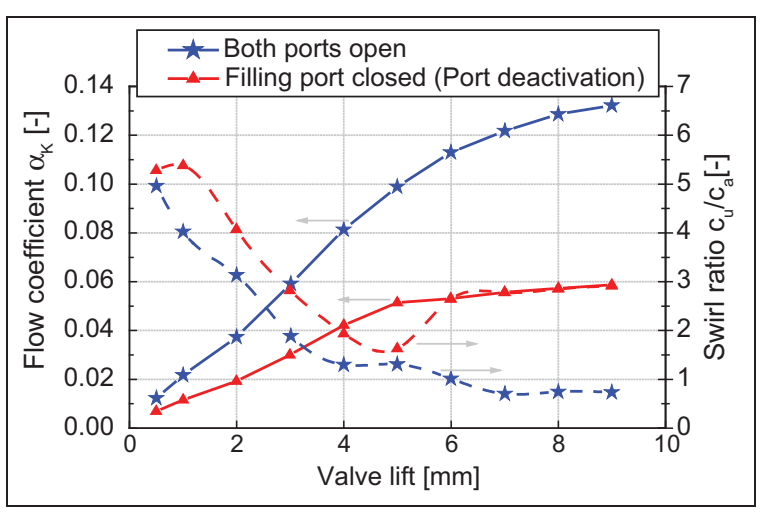

Figure I. Stationary measured flow coefficient and swirl ratio.

At low valve lifts, an increase of the swirl ratio due to the effect of the swirl chamfers is visible. The use of the seat swirl chamfers on both intake valves ensures a higher swirl ratio and charge motion at low valve lifts. Using this port concept in combination with a variable intake-valve-lift system enables us to adapt the swirl ratio at each operating point.

Four different maximum valve lifts from $3.2 \mathrm{~mm}$ to $8.0 \mathrm{~mm}$ are investigated. The intake valve opening (IVO) and IVC times are kept constant while the maximum valve lift is varied.

The experimental results of two important operating points $22801 / \mathrm{min}, 9.4$ bar indicated mean effective pressure (IMEP) and $15001 / \mathrm{min}, 4.3$ bar IMEP $^{6}$ are introduced briefly in this section. These two operating points are selected for the numerical analysis because they are most frequently used in the new European driving cycle (NEDC) and federal test procedure (FTP) 75 cycles, and are therefore significant for the total engine-out emissions of these cycles. Start of injection is kept constant and exhaust gas recirculation (EGR) rate is varied. More discussion and comparison with CFD results will be given in the following sections.

Figure 2 illustrates that the reduction of the intake valve lift from $8.0 \mathrm{~mm}$ to $4.8 \mathrm{~mm}$ significantly reduces smoke emission without any significant impact on fuel consumption for the $15001 /$ min operating point. A further reduction of the valve lift to $3.2 \mathrm{~mm}$ leads to an increase of gas exchange losses, and results in an increased fuel consumption without any improvement of the soot emissions. Another strategy to maintain an increased swirl ratio is the filling port deactivation in combination with a dual $8.0-8.0 \mathrm{~mm}$ valve lift $(8.0 \mathrm{~mm}$ port deactivation (PD)). In this case, both the soot emissions are deteriorated with a negative impact on fuel consumption compared to the $4.8-4.8 \mathrm{~mm}$ valve lift.

The experimental investigations on the singlecylinder test engine for the operating point $22801 / \mathrm{min}$, 9.4 bar IMEP are summarized in Figure 3 . It can be observed in the figure that reducing the maximum valve lift from $8.0 \mathrm{~mm}$ to $4.8 \mathrm{~mm}$ slightly improves the soot emissions. The $8.0 \mathrm{~mm}$ PD valve strategy produces a high amount of soot emissions similar to the $8.0 \mathrm{~mm}$

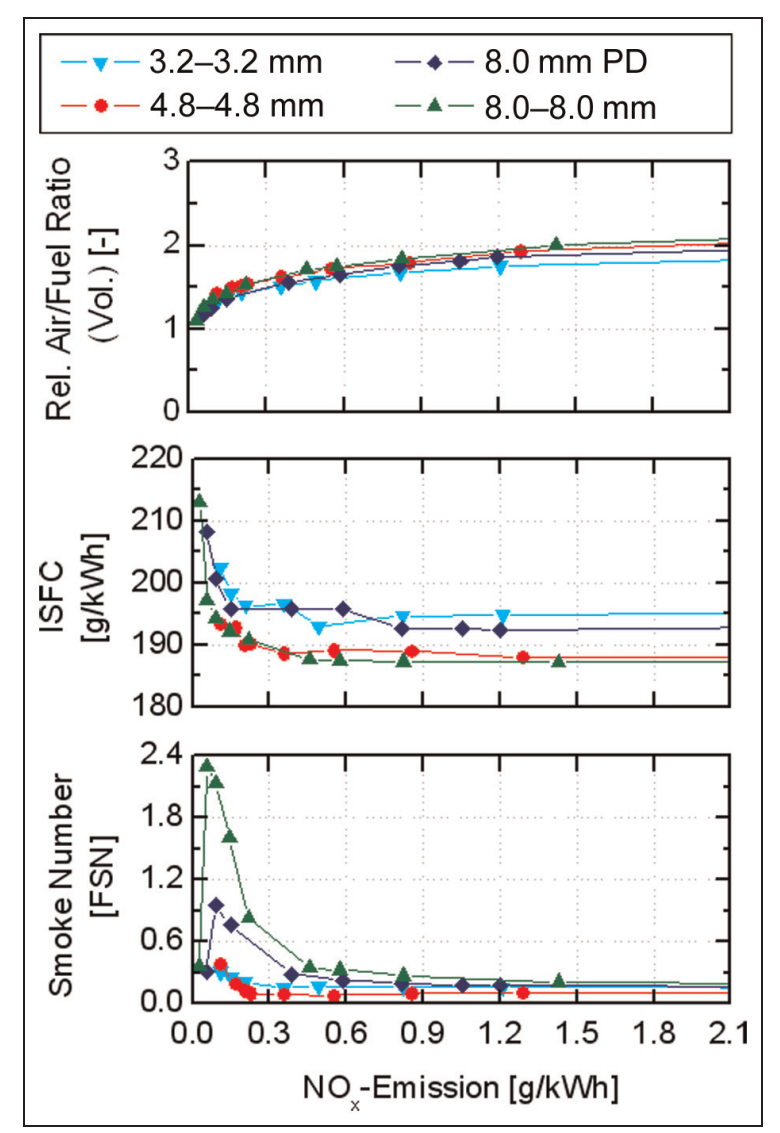

Figure 2. Experimental observations of the effect of increasing the swirl ratio on emissions and fuel consumption, $\mathrm{n}=1500 \mathrm{I} / \mathrm{min}, \mathrm{IMEP}=6.8$ bar. $^{6}$ Reprinted with permission from SAE paper 2009-0I-0653 @ 2009 SAE International. ISFC: indicated specific fuel consumption; FSN: fuel smoke number.

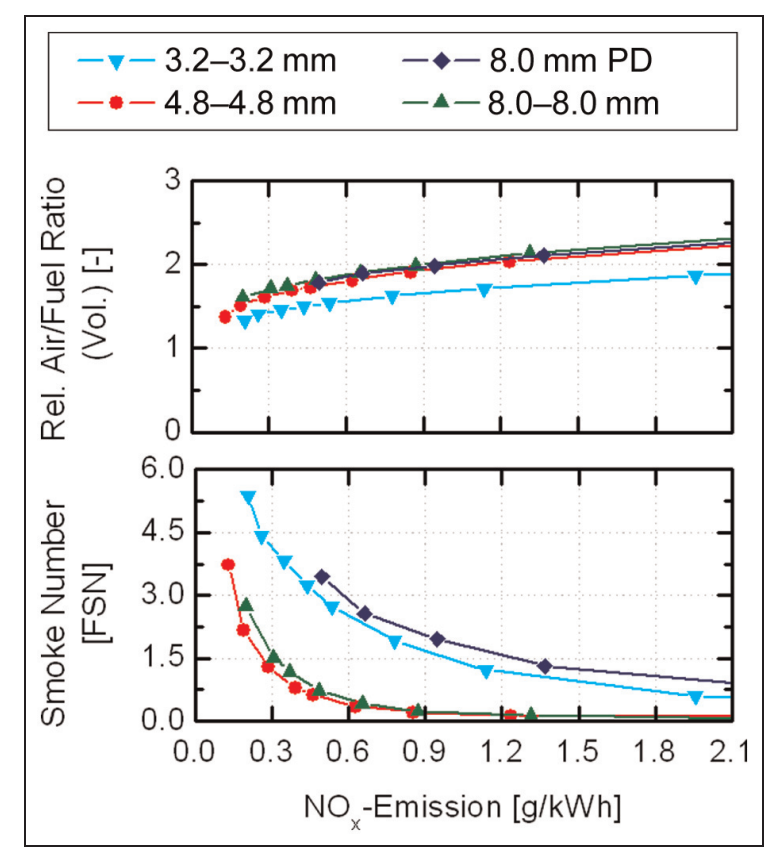

Figure 3. Experimental observation of the effect of increasing the swirl ratio on emission and fuel consumption, $n=2280 \mathrm{I} / \mathrm{min}$, IMEP=9.4 bar. $^{6}$ Reprinted with permission from SAE paper 2009 0I-0653 (c) 2009 SAE International. FSN: fuel smoke number. 


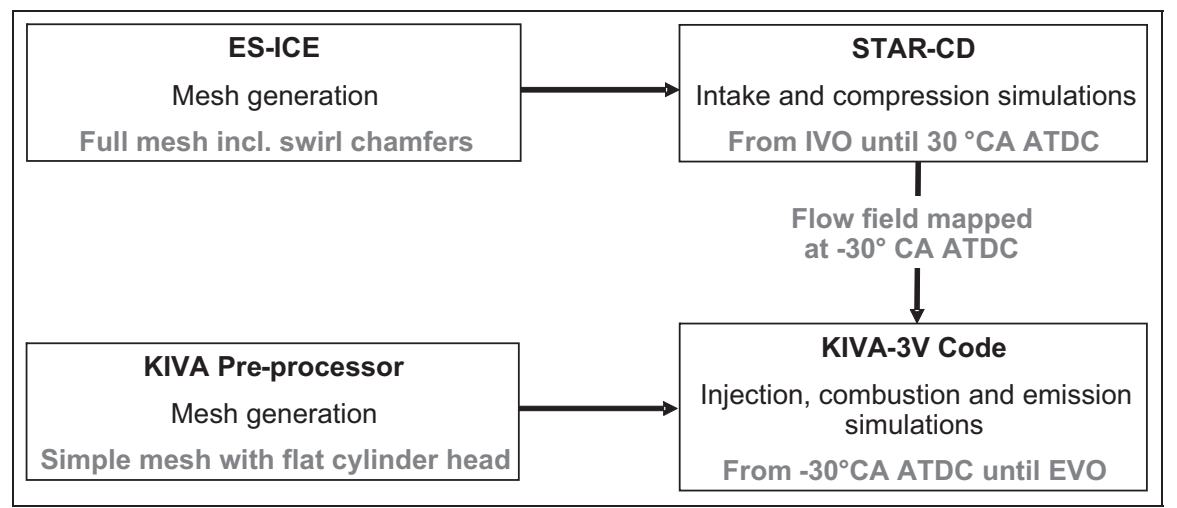

Figure 4. The applied simulation strategy.

dual valve lift. The reasons will be discussed in the next sections.

\section{Simulation procedure and numerical models}

In this study, the KIVA-3V release 2 code, ${ }^{7}$ with further developments by the Engine Research Center of Wisconsin University, ${ }^{8}$ is used for injection and combustion simulation. Due to the availability of the source code, this is used for implementation of the one-equation LES approach. Additionally, the code is extended by further soot and $\mathrm{NO}_{x}$ emission models. However, the capability of the code to fully resolve complex geometries is limited. Therefore, in this work, the software STARCD / ES-ICE is combined with the KIVA code in order to simulate in-cylinder charge motion generation, including the complete engine geometry. In-cylinder intake and compression simulation are carried out with the STAR$\mathrm{CD}$ software. The simulated in-cylinder flow field is then mapped onto a mesh of the KIVA code shortly before start of injection. A schematic of the simulation chain is depicted in Figure 4.

For in-cylinder flow and combustion simulation, both the RANS model and the LES approach are applied. The renormalization group (RNG) $k-\varepsilon \operatorname{model}^{8}$ is used in the KIVA code in the case of RANS simulation. Time averaging of the Navier-Stokes equations, commonly referred to as 'Reynolds averaging' greatly reduces the computational time, as it filters out the transient spectrum of turbulence, which is modelled instead. Therefore, it is recognized that time-averaging models do not have the ability to capture cycle-to-cycle variations in the flow field inside the combustion chamber accurately. More details about the RANS approach, its applications and limitations are given, for example, by Launder and Spalding ${ }^{9}$ and Bardina et al. ${ }^{10}$

The LES approach is a numerical technique to close the equations of turbulent flows by using spatial filtering. In the LES approach, larger turbulent structures (eddies) are directly calculated in a space- and timeaccurate manner, while smaller eddies that are smaller than a filter length are modelled using sub-grid scale (SGS) models. By applying the LES approach, unsteady flow and engine cyclic variations can be resolved, while a RANS simulation averages out many cyclic phenomena. More details can be found, for example, in Sone et al. ${ }^{11}$

In this study, the $k$-equation SGS model ${ }^{12}$ is implemented into the KIVA-3V code. For brevity, the governing equations and model formulation are not given here and can be found in Sone et al., ${ }^{13}$ with more details.

The multi-cycle intake flow simulations in STAR$\mathrm{CD}$ are carried out using the LES Smagorinsky model ${ }^{14}$ from IVO to $30^{\circ}$ crank angle (CA) after top dead centre (ATDC). Numerical simulation of injection, combustion and emission formation are subsequently carried out by the KIVA-LES code using the simulated incylinder flow field from STAR-CD.

The applied spray atomization model accounts for combined Kelvin-Helmholtz and Rayleigh-Taylor droplet instabilities. ${ }^{8} \mathrm{~A}$ phenomenological nozzle flow model ${ }^{15}$ considering the nozzle passage inlet configuration is used. The commonly so-called 'Shell' five-species autoignition kinetic mode ${ }^{16}$ in combination with the characteristic-time combustion model $^{8}$ is used for ignition and combustion modelling.

For modelling the soot emissions, the simple model of Hiroyasu and Kadota ${ }^{17}$ and a well-validated multistep soot model developed at the Institute for Combustion Engines at RWTH Aachen University ${ }^{18}$ are used. The phenomenological soot model is based on the eight-step soot formation of Kazakov and Foster ${ }^{19}$ and a three-step oxidation model. ${ }^{20}$

The gas sampling measurement as well as the LII and Raman laser diagnostic investigations were applied for local and time-dependent validation of the simulated gas temperature, as well as concentration of species like $\mathrm{CO}, \mathrm{O}_{2}$ and also the predicted soot emission inside the combustion chamber. ${ }^{18}$

Furthermore, for the operating point 1500 1/min discussed in the following, the applied combustion and soot models are evaluated by experimental results of ignition, flame propagation and local soot formation obtained from the LII and flame light emission measurement techniques, considering different valve strategies. ${ }^{21}$ 


\section{Boundary conditions}

The intake, compression and combustion simulations are carried out for following two operating points:

- $\quad$ engine speed $22801 / \mathrm{min}, 9.4$ bar IMEP;

- engine speed 1500 1/min, 6.8 bar IMEP.

Different valve strategies are simulated using both the RANS model and the LES approach for both operating points. For the case of $22801 / \mathrm{min}$, the following two valve actuation strategies are simulated:

- dual opening with $4.8-4.8 \mathrm{~mm}$ maximum valve lift $(4.8-4.8 \mathrm{~mm})$;

- dual opening with $8.0-8.0 \mathrm{~mm}$ maximum valve lift, but with port deactivation by closing the filling port (8.0 mm PD).

For each of the above valve actuation strategies 10 cycles are simulated using the LES approach. The boundary conditions, such as wall temperatures, are kept the same for each valve strategy during the multicycle simulations.

Figure 5 shows the measured intake pressure curves and its standard deviation of 10 cycles with $4.8-4.8 \mathrm{~mm}$ maximum valve lift, which are directly applied as boundary conditions to the CFD simulations. There are very small perturbations in the measured intake pressure boundary conditions. These perturbations

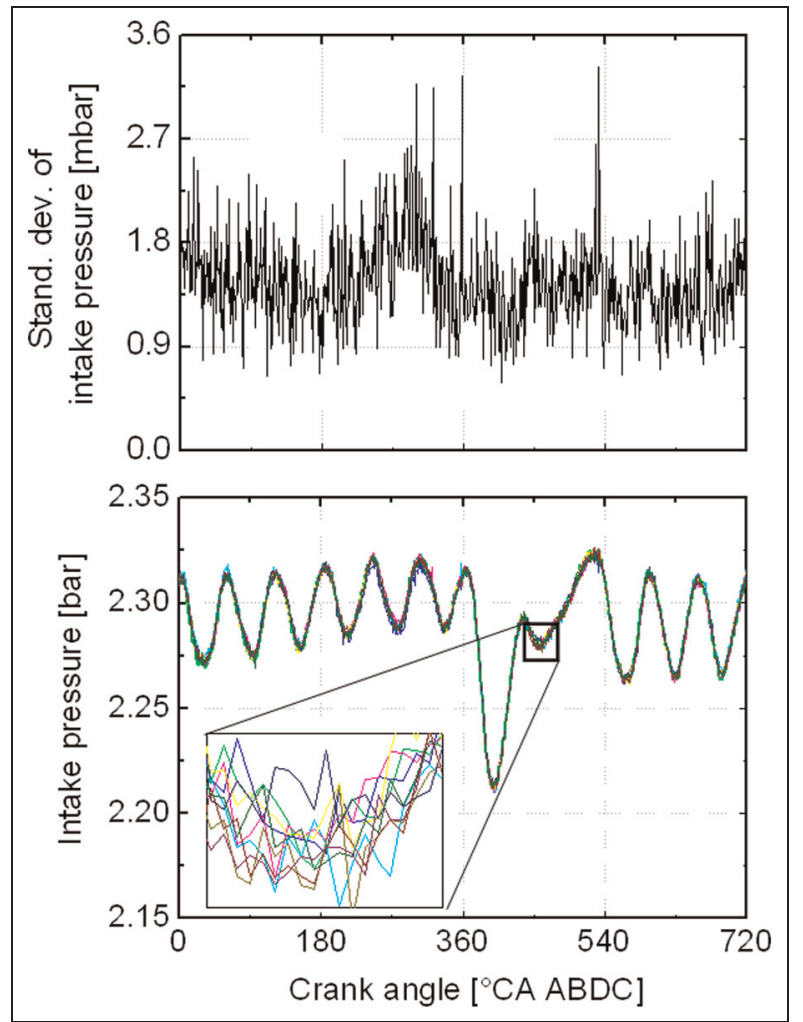

Figure 5. Measured and standard deviation of intake pressure boundary condition, $4.8-4.8 \mathrm{~mm}, \mathrm{n}=2280 \mathrm{I} / \mathrm{min}$, IMEP=9.4 bar. $A B D C$ : after bottom dead centre. finally cause stochastic variations in the in-cylinder flow structures on the microscopic and intermediate length and time scales. The result are cycle-to-cycle variations, for example, in terms of the flow in-homogeneity. In the LES approach, such small perturbations and fluctuations in flow turbulence are not filtered out as in the RANS model. Furthermore, previous work ${ }^{6}$ showed that flow structures predicted by LES approaches exhibit much stronger differences between different valve actuations strategies than RANS. This makes the LES an appropriate model for simulation and analysis of transient phenomena like engine cycle-to-cycle variability.

The second operating point investigated in this work is $15001 / \mathrm{min}$ with 6.8 bar IMEP. Three valve strategies $8.0-8.0 \mathrm{~mm}, 8.0 \mathrm{~mm}$ PD and $4.8-4.8 \mathrm{~mm}$ are selected for the numerical investigations applying the RANS and the LES approach. For brevity, only the cycleaveraged intake pressure curves of the three valve strategies are depicted in Figure 6.

\section{Computational mesh}

In this study, a complete mesh consisting of intake and exhaust ports, seat swirl chamfers, piston and a cylinder head for different valve strategies is generated by the ES-ICE software and applied in STAR-CD for intake and compression flow simulation. As depicted in Figure 7(a), the grid used for intake and compression simulation extends exactly to the intake pressure sensor location in order to use the measured intake pressure as boundary conditions of the simulation.

A good level of mesh resolution is essential for accurate turbulence modelling employing the LES approach. The quality of the computational grid used is evaluated with two different methods, ${ }^{21}$ which are not given here for brevity. For the a priori analysis, the size of the large energy containing eddies obtained by the RANS model is compared with the grid size in the intake ports and the combustion chamber. ${ }^{21}$ It is shown by Rezaei ${ }^{21}$ that the mesh resolution during the intake phase at some local positions, like near valve regions,

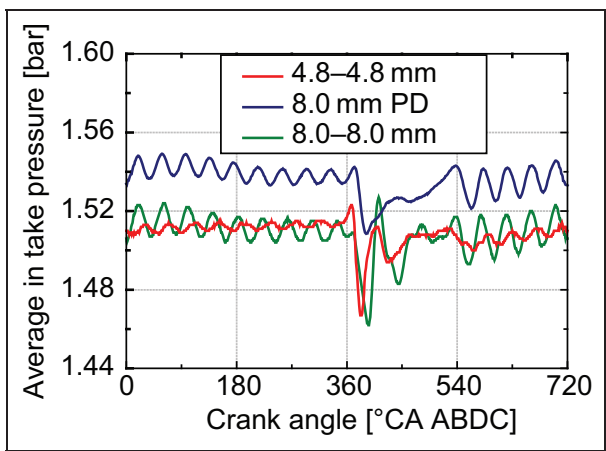

Figure 6. Averaged intake pressure boundary condition of all simulated valve strategies, multi-cycle, $n=1500 \mid / \mathrm{min}$, IMEP=6.8 bar. 


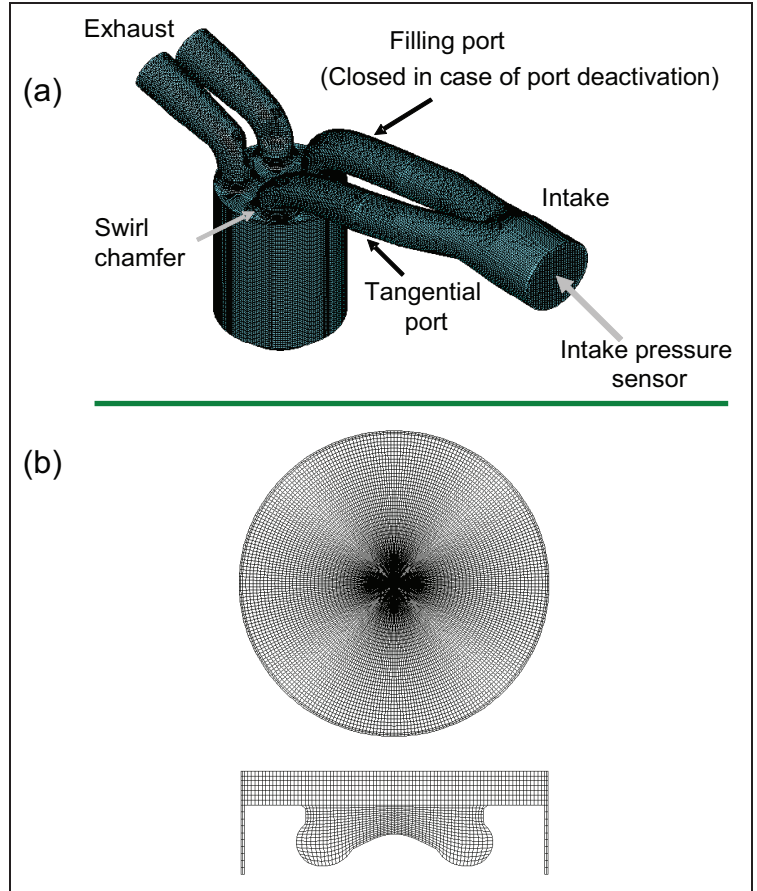

Figure 7. Computation meshes applied in this study. (a) Full geometry mesh used for intake and compression simulation by STAR-CD. (b) Full cylinder mesh applied in the KIVA code for injection and combustion simulation.

Table 2. Mesh types and number of computational cells.

\begin{tabular}{ll}
\hline Mesh type & Number of cells \\
\hline STAR-CD & 935,000 \\
KIVA & 450,000 \\
\hline
\end{tabular}

must be improved. As a further evaluation, it is shown that the amount of the turbulent kinetic energy directly resolved by the LES approach is about $85-90 \%$ of the total turbulent kinetic energy in the intake and compression phase. $^{21}$

Figure 7(b) illustrates the side and top view of the mesh used in KIVA at the mapping point $-30^{\circ} \mathrm{CA}$ ATDC. A summary of the number of computational cells used in each mesh type is given in Table 2.

\section{Results}

Traditionally, charge motion in diesel engines is described by the swirl ratio, which is a global measure obtained by integration of the swirl momentum in the entire combustion chamber. Recent experimental and numerical investigations have shown that inhomogeneity and local differences in the in-cylinder flow structure have noticeable impacts on combustion and emissions. In the following sections, the effects of different flow structures generated by different swirl generation strategies on combustion and hence emission behaviour are described.

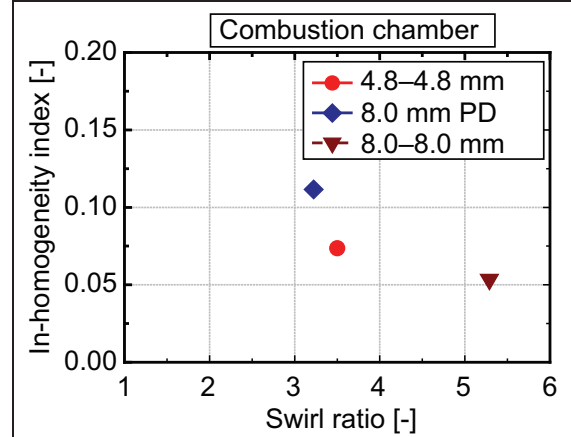

(a)

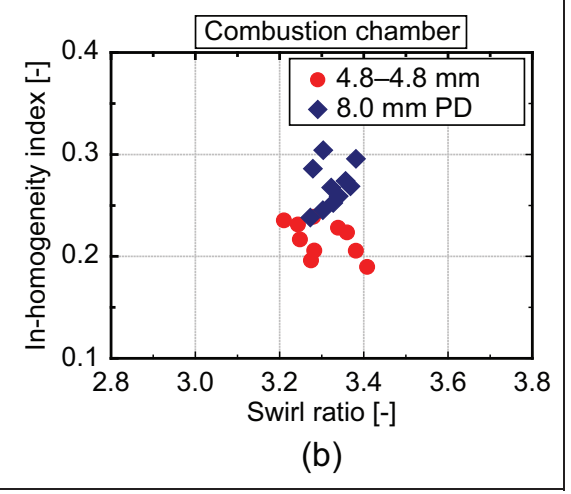

Figure 8. In-homogeneity index calculated for the complete combustion chamber, $n=2280 \mathrm{I} / \mathrm{min}, \mathrm{IMEP}=9.4$ bar: (a) RANS results and (b) LES results.

\section{Evaluation of in-cylinder flow and swirl quality}

The intake pressure is adjusted at the test bench in order to reach the same in-cylinder filling for both cases. For evaluation and assessment of the in-cylinder flow field in HSDI diesel engines, Adolph et al. ${ }^{6}$ introduced the homogeneity of the swirl flow as an additional criterion for quantitative assessment of swirl flow pattern and its homogeneity. Here, we will employ the definition of flow in-homogeneity as proposed in Adolph et al. ${ }^{6}$ The in-homogeneity, $I_{\text {in-hom }}$, is defined as the root mean square of the tangential in-cylinder flow velocity at each cross-section normalized by the absolute value of the flow-velocity component in the same tangential direction, averaged in the complete in-cylinder volume,

$$
I_{\text {in-hom }}=\frac{\sum_{\text {section }=1}^{N_{\text {section }}} R M S_{V_{\theta, \text { section }}} A_{\text {section }}}{\sum_{\text {section }=1}^{N_{\text {section }}} \bar{V}_{\theta, \text { section }} A_{\text {section }}}
$$

where $A_{\text {section }}$ is the area of the considered cross-section, $\bar{V}_{\theta \text {, section }}$ and $R M S_{V_{\theta \text {, section }}}$ are the mean and root mean square of the tangential velocity at the considered cross-section, respectively.

In other words, it is a measure of deviation of the in-cylinder swirl from a rigid-body rotation such that for a more in-homogeneous flow field, higher values of the in-homogeneity index are calculated. As already shown in Adolph et al. ${ }^{6}$ (see also Figure 8), applying 
the RANS and LES models, the variant $4.8-4.8 \mathrm{~mm}$ and the $8.0 \mathrm{~mm}$ PD valve strategies nominally lead to similar global swirl levels, but because of different flow structures, the calculated in-homogeneity indexes are different. The in-homogeneity index for the $4.8-4.8 \mathrm{~mm}$ valve strategy is lower than for $8.0 \mathrm{~mm}$ PD. For brevity, only the operating point $22801 / \mathrm{min}$ is considered.

As depicted in Figure 8, due to the capability of the LES approach in capturing the unsteady flow and transient phenomena that are not averaged out, as in the RANS model, the cycle-to-cycle variations in the incylinder flow homogeneity can be observed. The role of cyclic variation of in-cylinder flow field on combustion and emission behaviour is not discussed here for brevity, but is given in Rezaei ${ }^{21}$ with more details, including the experimental investigations.

The velocity magnitude at the cross-sectional view at the middle of the bowl, for two operating points $22801 / \mathrm{min}$ and $15001 / \mathrm{min}$ simulated by the RANS model as well as ensemble average results of the LES multi-cycle approach, are plotted in Figure 9. As is qualitatively illustrated in Figure 9, the velocity distribution in a circumferential section shortly before start of injection for the variant $8.0 \mathrm{~mm}$ PD is more inhomogeneous.

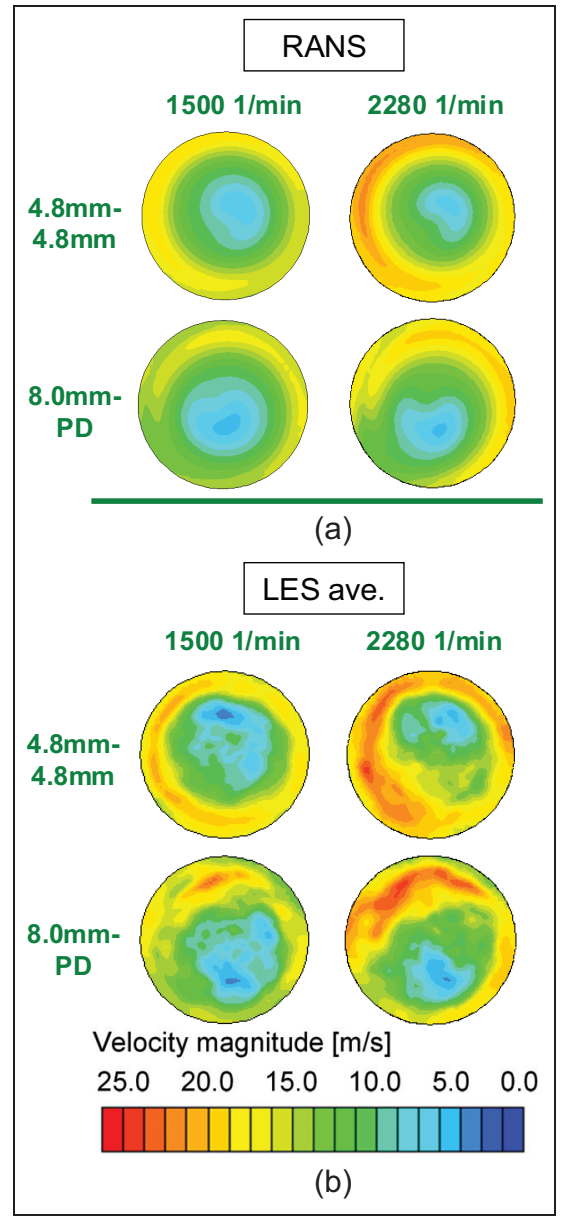

Figure 9. Cross-sectional view of the velocity magnitude at the middle of the bowl: (a) RANS results and (b) ensemble average LES results, $\mathrm{n}=2280$ and $\mathrm{I} 500 \mathrm{I} / \mathrm{min}$.

\section{The effect of in-cylinder flow on combustion and emissions}

In-cylinder swirl flow motion can enhance mixing processes, may lead to a more homogeneous mixture and, consequently, can improve emission formation. Increasing the swirl ratio (until an optimal value is achieved); for example, by means of combining the seat swirl chamfer and a reduction of the valve lift, leads to a better air-fuel mixing and mixture preparation, which decreases pollutant emissions. Another effect that is studied here in more detail is the in-homogeneity of the swirl flow pattern, which affects the distribution of mixture during the combustion process and hence the emission formation.

Numerical investigations of in-cylinder flow show that the variant $8.0 \mathrm{~mm}$ PD has a higher flow inhomogeneity than $4.8-4.8 \mathrm{~mm}$. A noticeable increase in the soot emissions was observed when comparing both valve strategies at the test bench. ${ }^{6}$ The results of numerical investigations of combustion and emission formation are presented in the following sections.

RANS modelling. Numerical simulations of injection, combustion and emission formation are carried out using a modified version of KIVA-3V release $2 .^{7}$ The two operating points given above are investigated.

$2280 \mathrm{I} / \mathrm{min}, 9.4 \mathrm{bar}$ IMEP. In order to study only the effect of the in-cylinder flow and to isolate other effects, all other operating conditions, in-cylinder mass, airfuel ratio, injection system, and so on, are kept the same for both valve strategies, $4.8-4.8 \mathrm{~mm}$ and $8.0 \mathrm{~mm}$ $\mathrm{PD}$ in the numerical and experimental investigations. The intake pressure was adjusted at the test bench to get the same in-cylinder air mass for both cases. The measured intake pressures are directly used in the CFD simulations. For the $8.0 \mathrm{~mm}$ PD case, both intake valves have $8.0 \mathrm{~mm}$ maximum lift and the filling port is closed. The operating conditions are summarized in Table 3. According to the measured EGR ratio, composition of the intake air is calculated.

Figure 10 compares the simulated pressure curves and the heat release rate of the operating point $22801 /$ min, 9.4 bar IMEP employing both the $4.8-4.8 \mathrm{~mm}$ and $8.0 \mathrm{~mm}$ PD valve strategies with the measurements carried out on the single-cylinder test engine. Good agreement is found between measured and simulated KIVA results.

Table 3. Engine operating conditions, $2280 \mathrm{I} / \mathrm{min}, 9.4 \mathrm{bar}$ IMEP.

\begin{tabular}{ll}
\hline Engine speed ( I/min) & 2280 \\
Lambda & 2.22 \\
EGR rate & $31 \%$ \\
IMEP (bar) & 9.4 \\
Injected mass (mg) & 19.6 \\
Rail pressure (bar) & 970 \\
Start of pilot injection $\left({ }^{\circ} \mathrm{CA}\right.$ ATDC) & -22.5 \\
Start of main injection $\left({ }^{\circ} \mathrm{CA}\right.$ ATDC) & -0.2
\end{tabular}




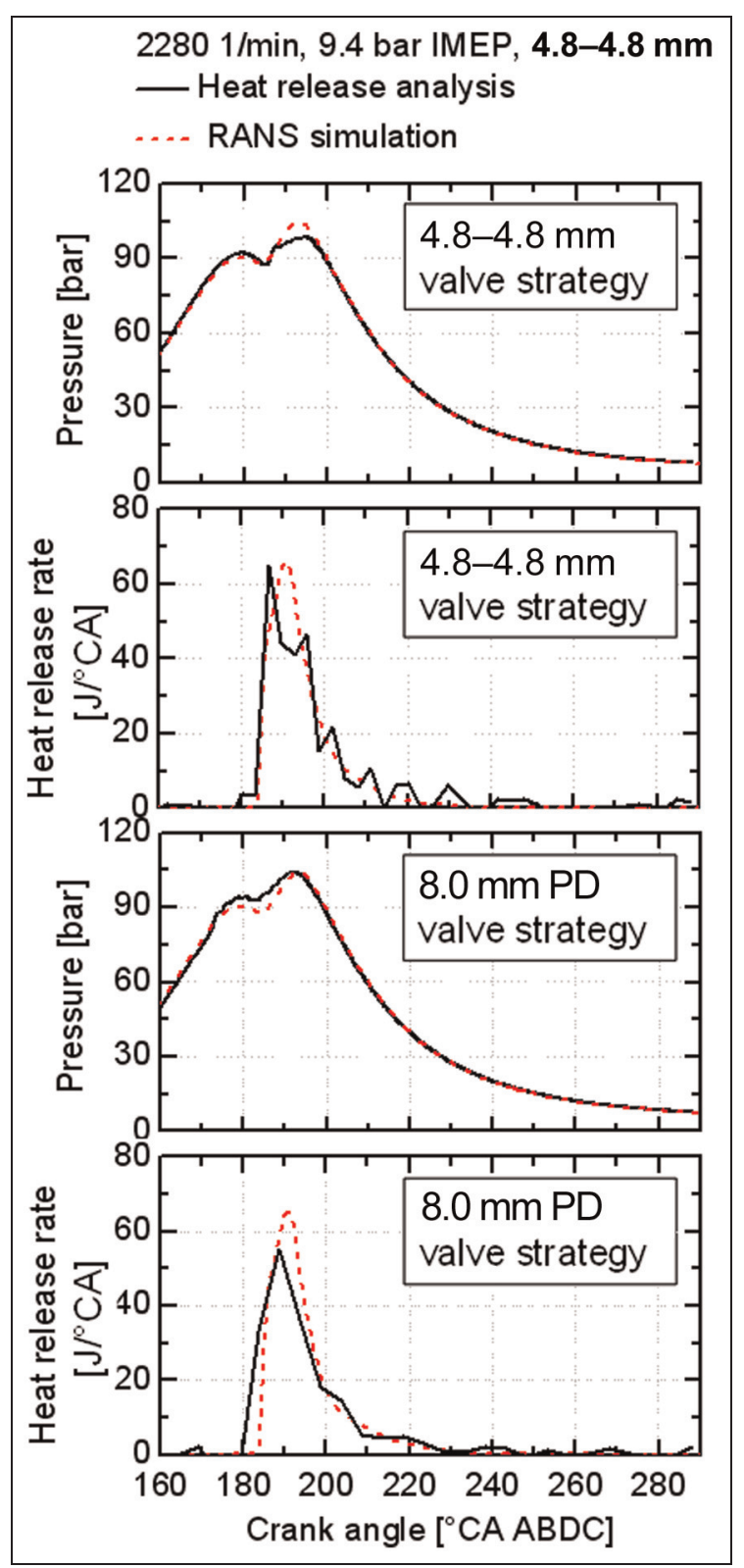

Figure 10. Heat release analysis of the CFD simulation using the RANS model in comparison with the engine measurement data at $\mathrm{n}=2280 \mathrm{I} / \mathrm{min}$, IMEP=9.4 bar.

The calculated in-cylinder emissions for both valve strategies are plotted in Figure 11. The transient curves of the soot concentration show first of all that the simple one-step soot model of Hiroyasu and Kadota ${ }^{17}$ fails to detect the observed trend of soot increase between the cases at the end of the exhaust stroke. In contrast, the phenomenological multi-step ${ }^{18}$ soot mechanism exhibits the difference between the two valve-lift strategies from approximately $16^{\circ} \mathrm{CA}$ ATDC. Furthermore, with this model, it is seen that before that crank angle position the soot concentration for the $4.8-4.8 \mathrm{~mm}$ valve strategy is predicted to be higher, but thereafter, the oxidation rate of soot is stronger for this strategy.

Another possibility to analyse the differences in mixture formation is the comparison in terms of air

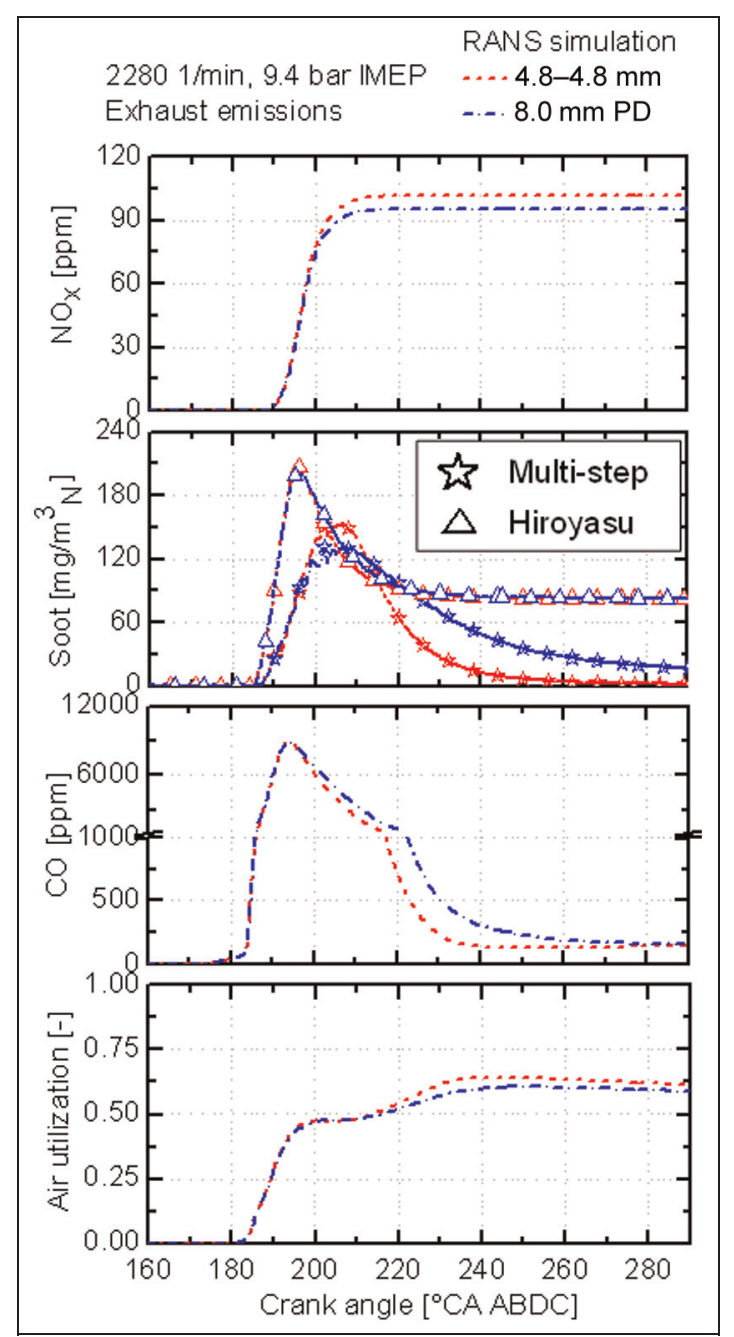

Figure I I. Calculated air utilization and emissions using the RANS model, $\mathrm{n}=2280 \mathrm{I} / \mathrm{min}$, IMEP=9.4 bar.

utilization. Air utilization is defined here as the volume fraction of mixture with a relative air-fuel ratio $\lambda$ between 0.0 and 2.0. For the $4.8-4.8 \mathrm{~mm}$ case, higher values of air utilization are calculated. On the other hand, there are only marginal differences in the $\mathrm{CO}$ and $\mathrm{NO}_{\mathrm{x}}$ emissions between both valve strategies.

In order to compare the simulated trend in the soot emissions with the observed trend on the test bench, both experimental and numerical investigations are now normalized to the corresponding $4.8-4.8 \mathrm{~mm}$ valve strategy. Figure 12 illustrates the trend of increased soot emissions by applying $8.0 \mathrm{~mm}$ PD instead of 4.8$4.8 \mathrm{~mm}$ valve lift, for both CFD predictions and measurements of the operating point $22801 /$ min and 9.4 bar IMEP. Both analyses show a significant increase in the same direction for soot emissions between the two different valve-lift strategies.

In order to analyse the mixture formation in a more detailed way, the air utilization is given in Figure 13, considering four different ranges in air-fuel ratio. The difference between the two additional curves shows the volume fraction of the mixture with a lambda value 


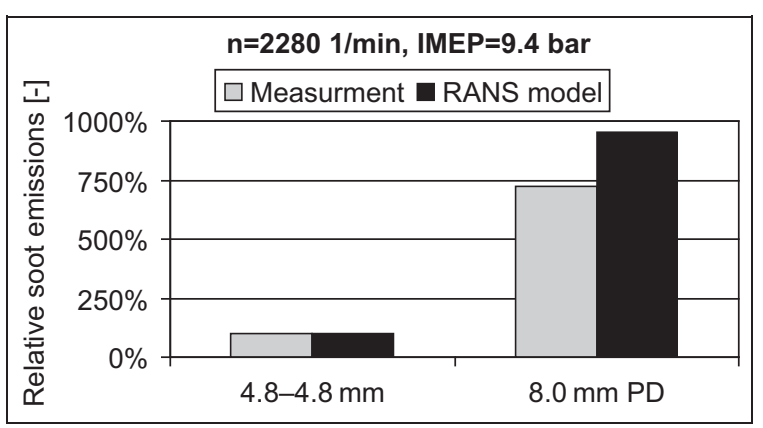

Figure 12. Increase in soot emissions due to applying the $8.0 \mathrm{~mm}$ PD swirl generation strategy. All investigation strategies are normalized to the corresponding $4.8-4.8 \mathrm{~mm}$ strategy, RANS model, $\mathrm{n}=2280 \mathrm{I} / \mathrm{min}$, IMEP $=9.4 \mathrm{bar}$.

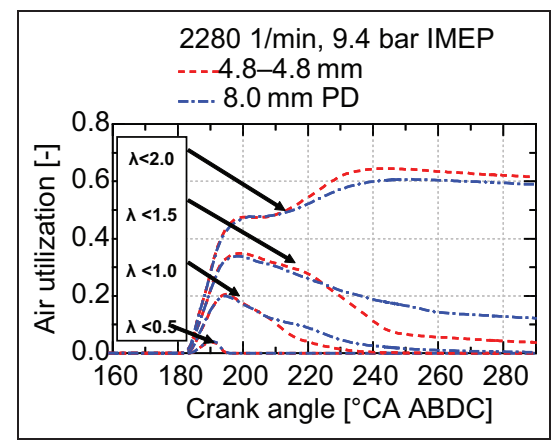

Figure 13. Comparison of the detailed air utilization between $4.8-4.8 \mathrm{~mm}$ and $8.0 \mathrm{~mm}$ PD strategies, RANS model, $\mathrm{n}=2280 \mathrm{I} / \mathrm{min}$, IMEP=9.4 bar. The difference between two curves for one strategy visualizes the strength of a specific $\lambda$ class.

between 0.5 and 1.0, representing the rich mixture, which is mainly responsible for soot formation in diesel engines. ${ }^{18}$ The differences in this class between these two valve strategies appear at about $30^{\circ} \mathrm{CA}$ ATDC.

In the case of $8.0 \mathrm{~mm} \mathrm{PD}$, after $30^{\circ} \mathrm{CA}$ ATDC, a considerably greater volume of rich mixture is found, which remains longer in the combustion chamber than in the $4.8-4.8 \mathrm{~mm}$ case. Consequently, this results in a higher amount of soot emissions.

To further understand the observed effect, the histogram of the mass distribution over relative air-fuel ratio $\lambda$ (lambda class diagram) and the top view of the soot iso-volume with concentration greater than a given threshold are plotted in Figure 14. As depicted in Figure 14, at $16^{\circ} \mathrm{CA}$ ATDC, only a marginal eccentricity in soot clouds for the $8.0 \mathrm{~mm}$ PD case is visible. In particular, starting at $30^{\circ} \mathrm{CA}$ ATDC, an eccentric soot cloud is visible which is not homogeneously distributed in the combustion chamber, compared to the 4.8 $4.8 \mathrm{~mm}$ case.

The differences in soot emissions between 4.8$4.8 \mathrm{~mm}$ and $8.0 \mathrm{~mm}$ PD appear mainly in the oxidation phase. The lambda class diagram shows that at $16^{\circ} \mathrm{CA}$ ATDC, there are marginal differences between both valve strategies. The differences are becoming more pronounced from $30^{\circ} \mathrm{CA}$ ATDC. At this time, it is shown that the case port deactivation has more mass fraction in the lambda region between 0.7 and 1.0, which is responsible for the soot formation and at the same time less mass fraction in the lambda region between 1.0 and 1.5, which is responsible for the soot oxidation. The differences between the two cases are further increased at $35^{\circ} \mathrm{CA}$ ATDC. It is seen that at $45^{\circ} \mathrm{CA}$ ATDC, the main parts of the soot emissions for the $4.8-4.8 \mathrm{~mm}$ case are oxidized, and for the $8.0 \mathrm{~mm}$ PD case, the soot emissions remain in the bowl volume.

LES multi-cycle approach. In LES, the large energy containing motion caused by the large eddies is directly simulated, and the effect of small-scale fluctuations is modelled. It makes the LES model more appropriate for capturing the transient phenomena such as engine cyclic variations.

In comparison to the RANS, which has a rich tradition in injection and combustion modelling, a high degree of effort may be required for adaptation or even reformulation of current injection, combustion and emission formation models, which are mainly based on RANS modelling, into LES. In case of using these models with LES, another question is whether they can predictively simulate the combustion process or even the emission behaviour of a diesel engine.

A part of this study is associated with the implementation and application of the LES approach, as well as an evaluation of its applicability and predictability in diesel engines with regards to available numerical models and computational resources. Therefore, the combustion and emission models originally developed for the RANS modelling are simply taken and used with the implemented LES approach. Numerical results of injection and spray formation are validated against experimental investigations at a high-pressure chamber. ${ }^{21}$

The turbulent 'law-of-the-wall' was used as the wall boundary condition. The focus of this work here was not to resolve the wall layer of the in-cylinder flow with a suitable LES mesh or model, but rather attention was paid to the instabilities and fluctuations in the bulk flow. However, the application of models developed for wall bounded flows, such as the wall-adapted local eddy-viscosity (WALE) model, ${ }^{22}$ can better reproduce the asymptotic behaviour of the turbulence at the wall.

As discussed before, the numerical results of the intake and compression simulation by applying the LES approach in STAR-CD, illustrated in Figure 8, show an increase in flow in-homogeneity due to applying the valve-lift strategies as the RANS approach. In Figure 15, a comparison of the pressure curve and the heat release rate obtained from measurements and its thermodynamic analysis and considering four cycles simulated by the LES approach is shown. A good agreement between CFD results and measured data are found for both valve strategies. The observed cycle-tocycle variations of in-cylinder pressure and heat release rate are small. 


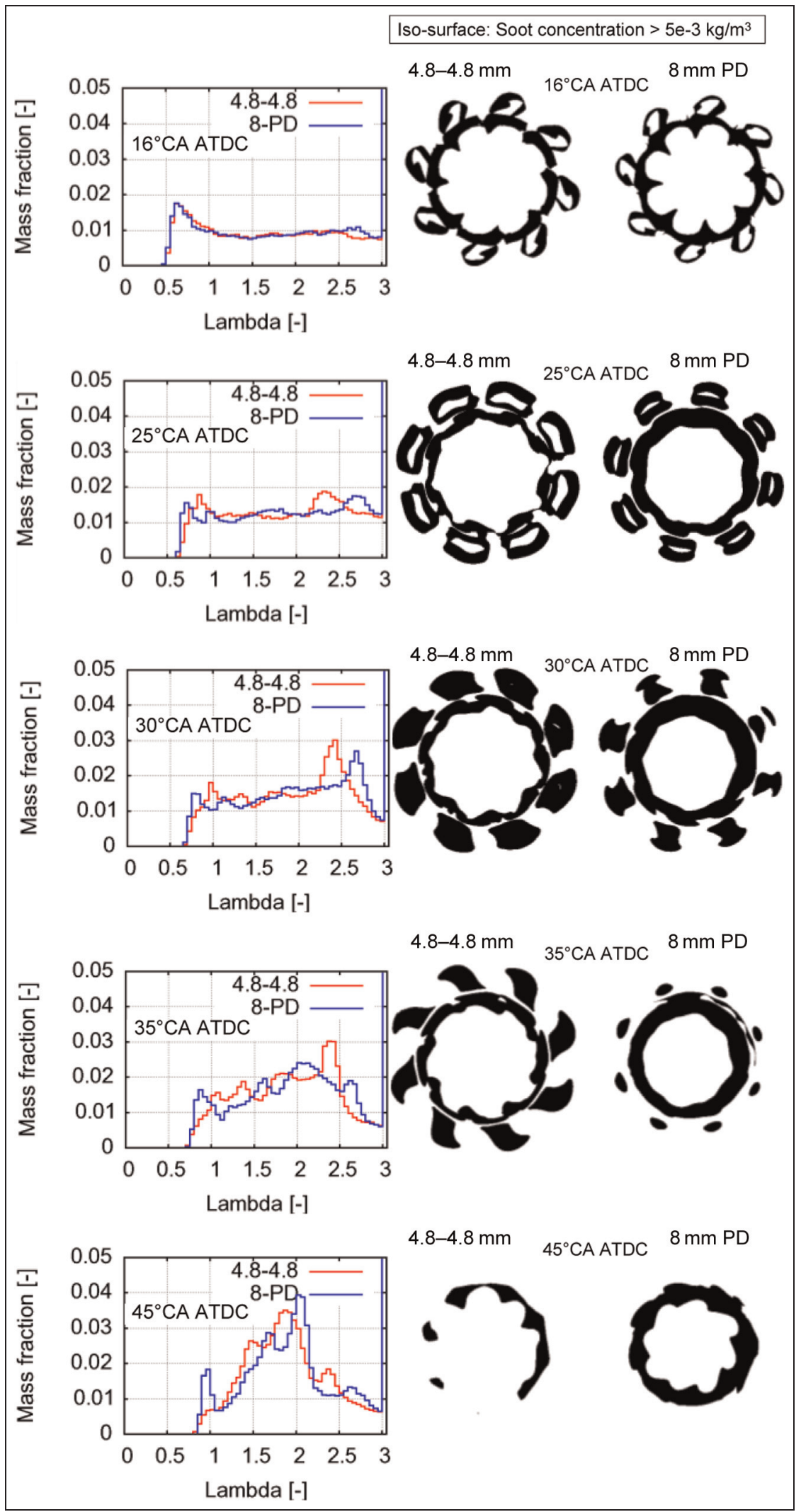

Figure 14. Mass fraction distribution diagram and top view of the iso-volume of soot concentration with a soot concentration higher than $5 \times 10^{-3} \mathrm{~kg} / \mathrm{m}^{3} \mathrm{~N}$, RANS model, $\mathrm{n}=2280 \mathrm{I} / \mathrm{min}$, IMEP=9.4 bar.

The in-cylinder soot emissions are depicted in Figure 16 for the $4.8-4.8 \mathrm{~mm}$ valve lift, employing both the multi-step ${ }^{18}$ and Hiroyasu and Kadota ${ }^{17}$ soot formation models. Again, the multi-step soot model predicts the measured value better than the Hiroyasu and Kadota single-step model. Cycle-to-cycle variations in the predicted soot emission are observed. Here, we want to isolate the effect of swirl flow pattern from other effects 


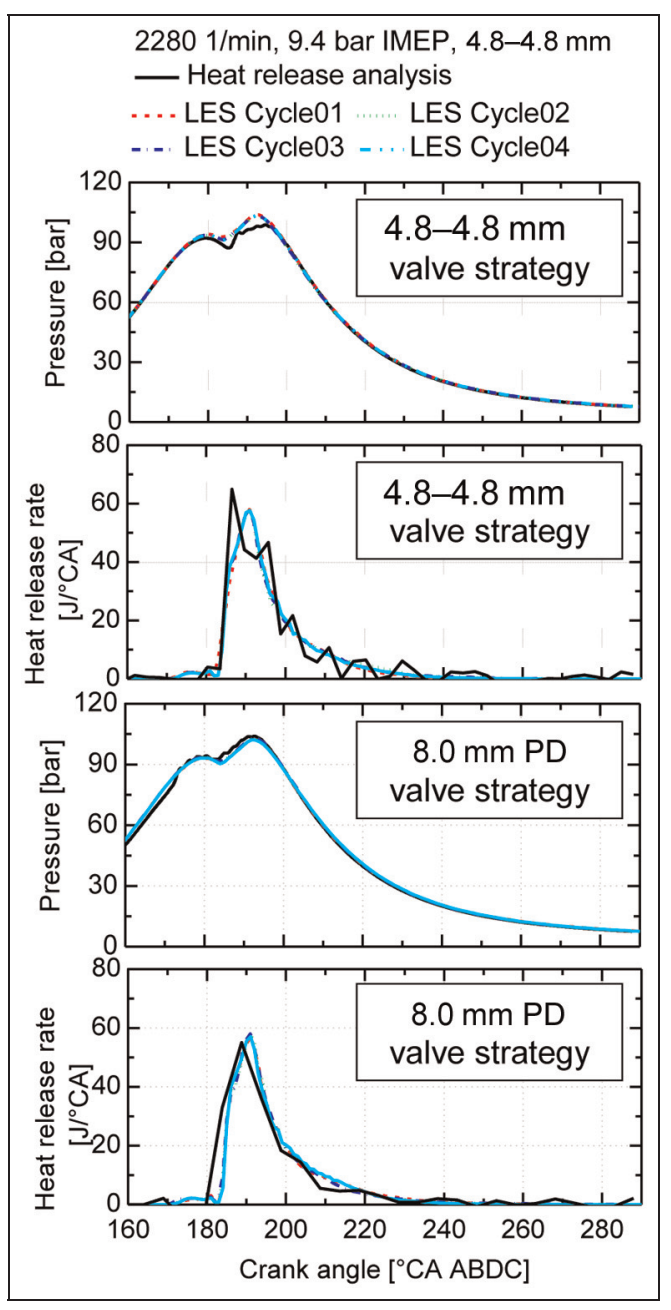

Figure 15. Heat release analysis of the engine measurement data in comparison to the CFD simulation employing the LES approach at $\mathrm{n}=2280 \mathrm{I} / \mathrm{min}$, IMEP=9.4 bar.

like cyclic variations of the injection system EGR ratio and gas composition. For these quantities, cycle-tocycle variations in initial and boundary conditions are not considered; this does not imply that the authors deny them. Here, in CFD, the observed fluctuations are intended only due to cycle-to-cycle variations of the incylinder flow. However, cycle-to-cycle variations of injection characteristics, EGR ratio and gas composition could be a major cause of fluctuations.

The analogous comparison of engine-out soot emissions as Figure 12 for RANS is carried out for LES in Figure 17. Here, the predicted level of soot increase obtained by the LES approach is less than the measured trend.

The detailed air utilization between both valve strategies simulated by the LES is given in Figure 18. For more clarity, only the first cycle among the whole 10 simulated LES cycles is shown.

Similar to the detailed air utilization obtained by RANS modelling, the $8.0 \mathrm{~mm}$ PD case reveals a higher amount of rich mixture in the range of $0.5<\lambda<1.0$, which is mainly responsible for soot formation, and also a less lean mixture between 1.0 and 1.5 , which is

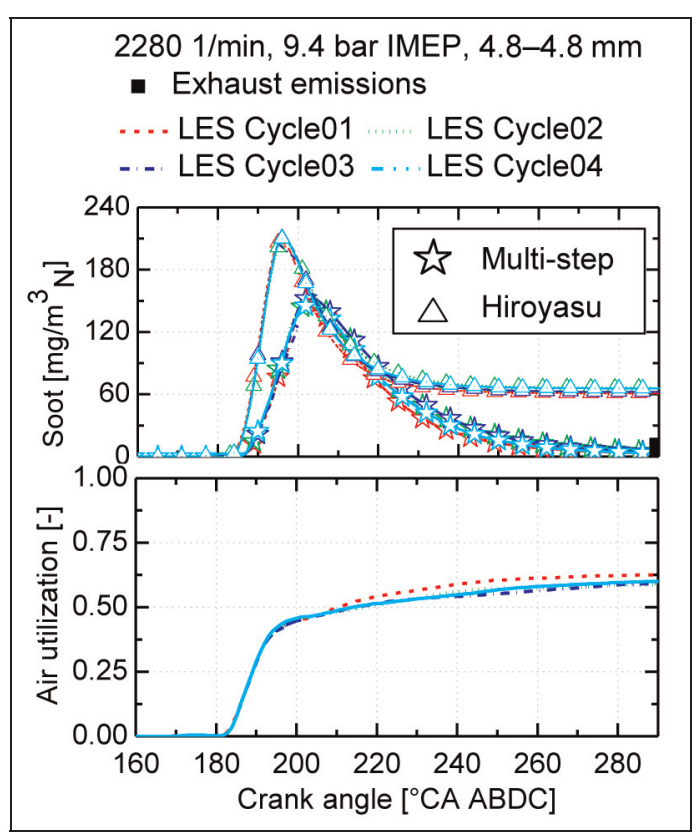

Figure 16. Simulated emissions applying the LES approach in comparison with measured data, $4.8-4.8 \mathrm{~mm}$ valve lift, $\mathrm{n}=2280 \mathrm{I} / \mathrm{min}$, IMEP=9.4 bar and air utilization for $\lambda<2$.

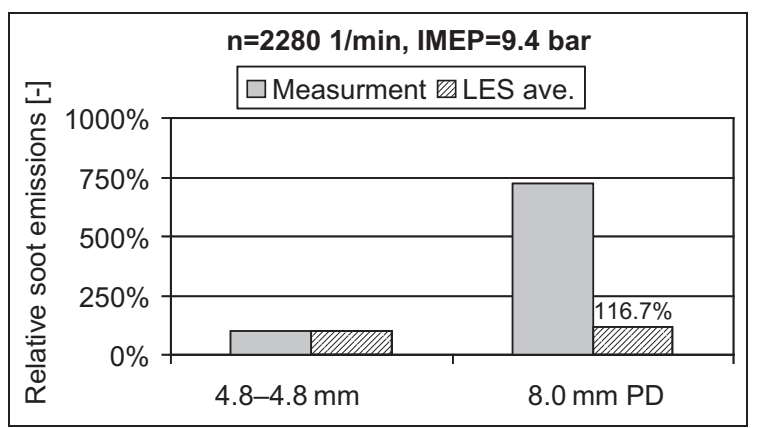

Figure 17. Increase in soot emissions due to applying the $8.0 \mathrm{~mm}$ PD swirl generation strategy. All investigation strategies are normalized to the corresponding $4.8-4.8 \mathrm{~mm}$ strategy, the LES multi-cycle approach, $\mathrm{n}=2280 \mathrm{I} / \mathrm{min}, \mathrm{IMEP}=9.4 \mathrm{bar}$.

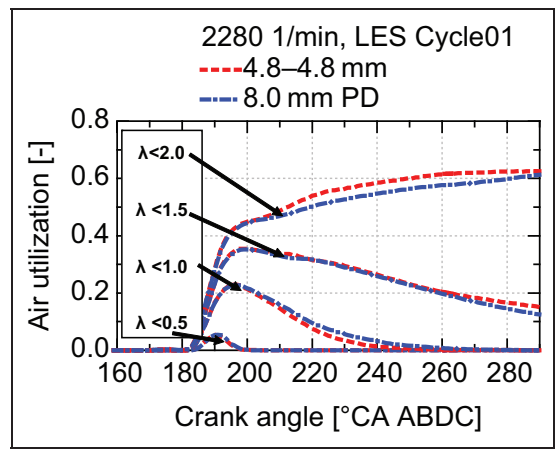

Figure 18. Comparison of the detailed air utilization between 4.8-4.8 $\mathrm{mm}$ and $8.0 \mathrm{~mm}$ PD strategies, the LES approach, $\mathrm{n}=2280 \mathrm{I} / \mathrm{min}, \mathrm{IMEP}=9.4 \mathrm{bar}$.

mainly responsible for the soot oxidation process. Like the simulation results obtained by the RANS model, the differences between both valve strategies are 


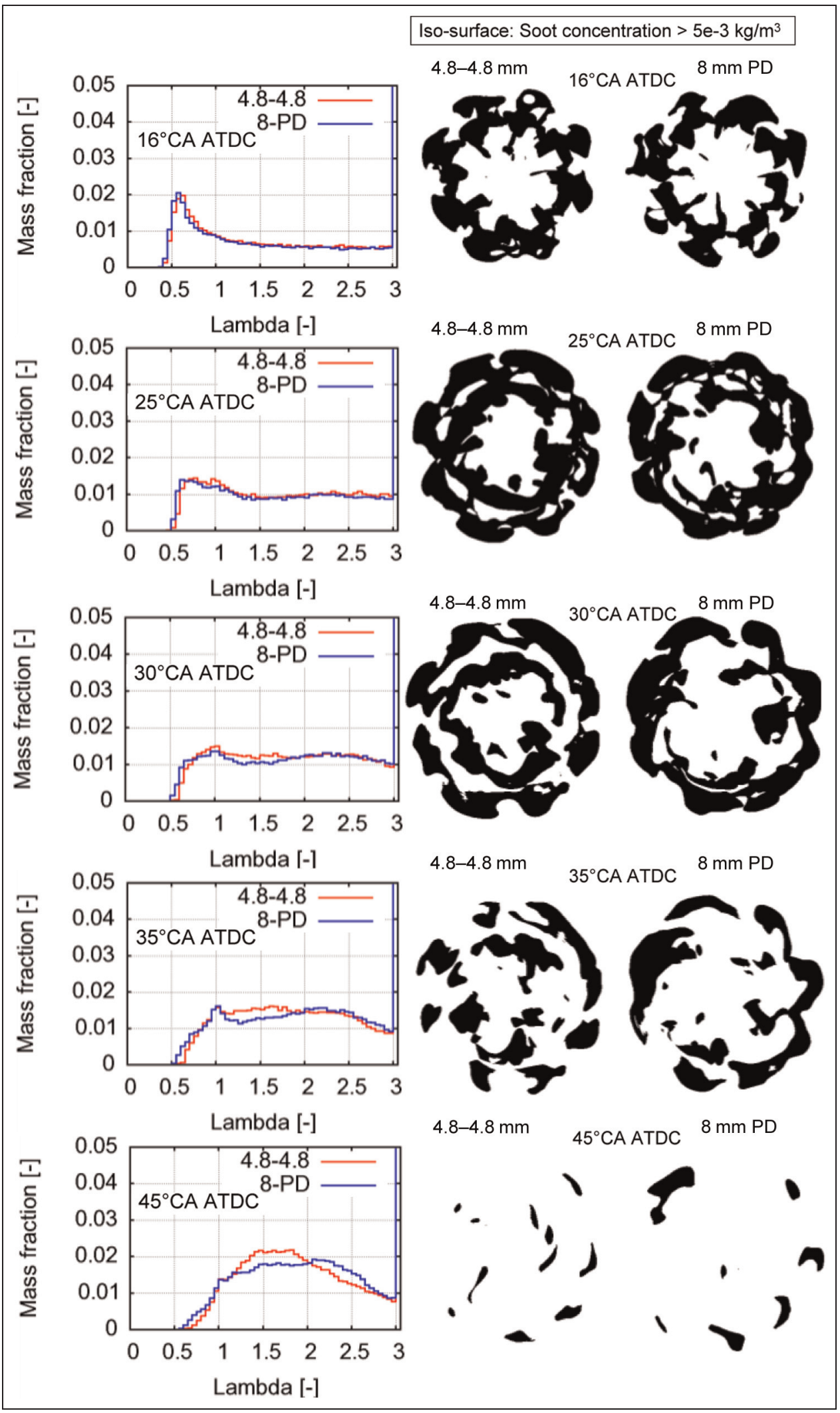

Figure 19. Mass distribution histogram over relative air-fuel ratio and top view of the iso-volume of soot concentration employing the LES approach, $n=2280 \mathrm{I} / \mathrm{min}, \mathrm{IMEP}=9.4 \mathrm{bar}$. The soot iso-volume is given for a concentration of $5 \times 10^{-3} \mathrm{~kg} / \mathrm{m}^{3} \mathrm{~N}$.

marginal at the beginning, but increase later in the oxidation phase. Similar to the RANS results, the mass over $\lambda$ histogram and the top view of the soot isovolume are plotted in Figure 19.
The differences between both valve strategies, similar to the RANS results, first appear in the oxidation phase. It is observable in Figure 19 that at $16^{\circ} \mathrm{CA}$ ATDC, the mass distribution histogram over relative 
air-fuel ratio between both cases is comparable, but divergence begins at $30^{\circ} \mathrm{CA}$ ATDC. At $35^{\circ} \mathrm{CA}$ ATDC, eccentric soot emissions are visible and the $8.0 \mathrm{~mm}$ PD case shows a higher mass fraction in the lambda region between 0.5 and 0.7 , which is critical for soot formation and also less mass fraction in the region between 1.0 and 1.5 , which is relevant for soot oxidation.

All the above observations show the effect of flow in-homogeneity on lambda class diagrams and also the soot clouds in the combustion chamber, such that (e.g. at $35^{\circ} \mathrm{CA}$ ATDC) an eccentric distribution of soot emissions is visible for the $8.0 \mathrm{~mm}$ PD case.

It is visible in Figure 19 that the results using the LES approach show differences in the air-fuel mixture in the lambda region between 0.5 and 0.7 between the two cases, which is important for generating soot pollutants. In comparison, the RANS simulation shows differences in the lambda region between 0.7 and 1.0 (see Figure 14). However, as depicted in Figure 17, the LES soot model cannot show the trend of the soot increase as is observed on the test bench. This will be discussed in the next section.

I 500 I/min, 6.8 bar IMEP. Additionally, the operating point $15001 / \mathrm{min}, 6.8$ bar IMEP for the same engine is investigated employing the same comparison of valvelift strategies. The operating conditions are summarized in Table 4.

The results of combustion simulation applying the RANS model, as well as the LES approach, in terms of predicting the trend of the soot emissions for the operating point $15001 / \mathrm{min}$, 6.8 bar IMEP are plotted in Figure 20. The numerical results performed with the

Table 4. Engine operating conditions, $1500 \mathrm{I} / \mathrm{min}, 6.8 \mathrm{bar}$ IMEP.

\begin{tabular}{ll}
\hline Engine speed ( $1 / \mathrm{min})$ & 1500 \\
Lambda & 1.6 \\
EGR rate & $44 \%$ \\
IMEP (bar) & 6.8 \\
Injected mass (mg) & 13.9 \\
Rail pressure (bar) & 900 \\
Start of pilot injection $\left({ }^{\circ} \mathrm{CA}\right.$ ATDC) & -15.5 \\
Start of main injection $\left({ }^{\circ} \mathrm{CA}\right.$ ATDC) & -4.0 \\
\hline
\end{tabular}

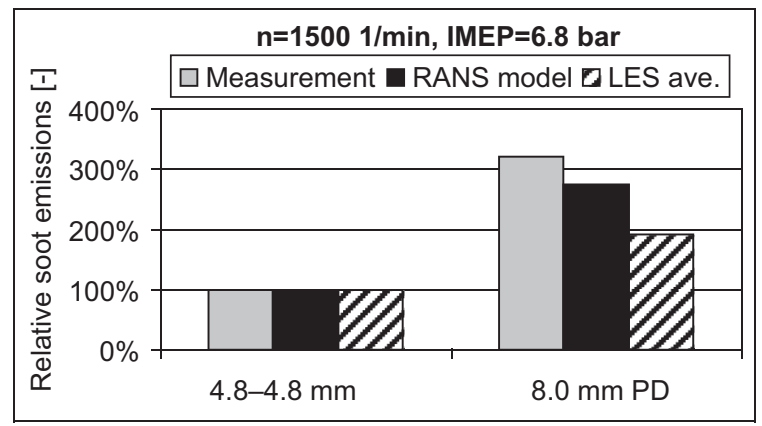

Figure 20. Increase in soot emissions due to applying the $8.0 \mathrm{~mm}$ PD swirl generation strategy. All investigation strategies are normalized to the corresponding $4.8-4.8 \mathrm{~mm}$ strategy, applying the LES approach and the RANS model, $\mathrm{n}=1500 \mathrm{I} / \mathrm{min}$, IMEP=6.8 bar.
RANS model show approximately the measured trend of a high increase in soot emissions due to applying the $8.0 \mathrm{~mm}$ PD.

Here, the LES approach better predicts the soot trend for the 15001/min case (Figure 20) than for the 2280 1/ min case (Figure 17). Figure 21 compares the lambda histogram between $4.8-4.8 \mathrm{~mm}$ and $8.0 \mathrm{~mm}$ PD valve strategies, considering one cycle at $35^{\circ}$ and $45^{\circ} \mathrm{CA}$ ATDC. As is illustrated in Figure 21, the differences between the two cases in the rich mixture, for $0.7<\lambda<1$ are visible, but also in the very lean mixture $\lambda>2.5$.

Mixture formation and iso-volume of different lambda classes simulated by RANS and LES are compared in Figure 22.

It is seen that the multi-step soot model ${ }^{18}$ can predict a reasonable trend in the emission between the two valve-lift strategies for the same operating point. For these cases, differences in the mixture exist in the airfuel ratio range between 0.7 and 1.0 (see Figures 12 and 14, as well as Figures 20 and 21). In the other case, if the air-fuel ratio distribution differences are predicted to be in the air-fuel ratio range between 0.5 and 0.7 , the multi-step soot model is less sensitive to these differences, and does not predict the right trend of soot increase (see Figures 17 and 19). We conclude that further development of the soot model should be a topic of future studies.

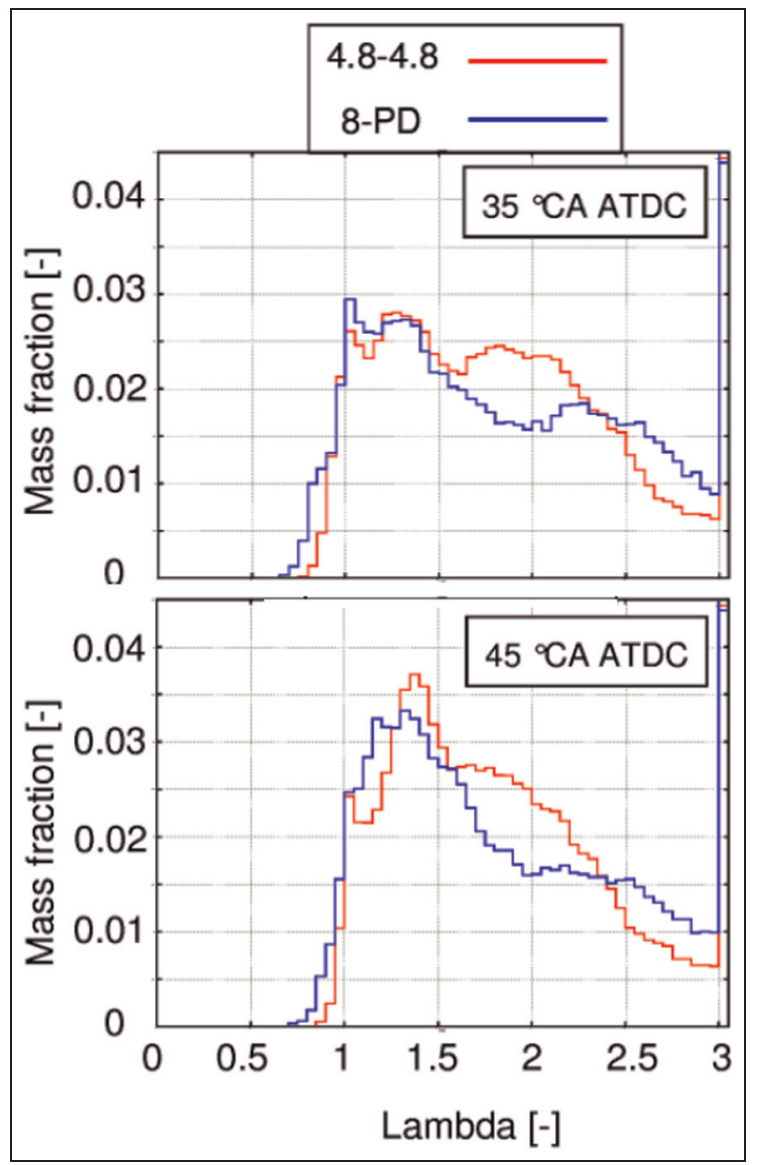

Figure 2I. Mass distribution histogram at 35 and $45^{\circ} \mathrm{CA}$ ATDC employing the LES approach, $n=|500| / / \mathrm{min}, I M E P=6.8 \mathrm{bar}$. 


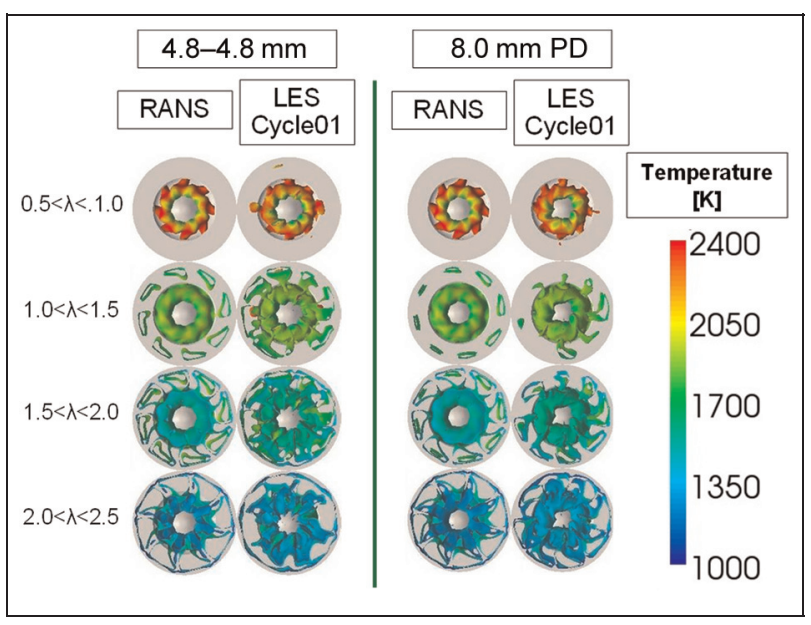

Figure 22. Mixture formation and iso-volume of different lambda classes simulated by the RANS and LES numerical techniques at $10^{\circ} \mathrm{CA}$ ATDC, $\mathrm{n}=1500 \mathrm{I} / \mathrm{min}$, IMEP $=6.8 \mathrm{bar}$.

\section{Conclusions}

This study is based on a systematic approach to affect the in-cylinder flow in a controlled manner, while maintaining identical combustion conditions using an identical chamber geometry and identical injection system. The in-cylinder swirl flow is enhanced by using reduced valve-lift curves and port deactivation, which both lead to a comparably increased swirl level, but substantial differences in the flow structure.

The effect of different valve strategies on swirl flow pattern is evaluated by applying the proposed methodology in the transient in-cylinder CFD simulation with the help of both the RANS and the LES approach.

The numerical simulation of in-cylinder flow using both the RANS and the LES approach have shown the same trend of flow in-homogeneity observed in the PIV measurements in previous investigations. ${ }^{2}$

The injection and combustion simulations of different valve strategies are carried out using the KIVA code with the in-cylinder flow field after the intake and compression stroke from STAR-CD. Numerical simulations have shown the observed trend in experimental investigations that an in-homogeneity in the in-cylinder flow structure leads to an extreme increase in the soot emissions. The differences in the soot emissions appear mainly in the oxidation phase such that the case with higher swirl in-homogeneity has an eccentric soot cloud that is not homogeneously distributed in the combustion chamber. This results in richer portions of air-fuel mixture in the cylinder as well as eccentric soot clouds. This is argued to be the reason why the overall soot emissions increase with flow in-homogeneity.

In this work, due to the capabilities of LES in capturing the transient phenomena and cyclic variations in diesel engines, the LES approach is implemented in the KIVA code. Injection, combustion and emission models developed for the RANS model are directly taken for the LES model. Combustion heat release results agree well with the measurement results. However, improvement of the quantitative predictability of the soot model, especially in combination with the LES approach, should be a topic of future research.

\section{Funding}

This work was performed as part of the Cluster of Excellence 'Tailor-Made Fuels from Biomass', which is supported by the Excellence Initiative by the German federal and state governments to promote science and research at German universities.

\section{Acknowledgements}

The authors would like to thank their colleagues at FEV Motorentechnik $\mathrm{GmbH}$ as well as the employees of the Institute for Combustion Engines, RWTH Aachen University, for their valuable help and technical support during this work.

\section{References}

1. Stephenson PW and Rutland CJ. Modeling the effects of valve lift profile on intake flow and emissions behavior in a direct injection diesel engine. SAE paper 952430, 1995.

2. Bianchi GM, Richards K and Reitz RD. Effects of initial conditions in multidimensional combustion simulations of HSDI diesel engines. SAE paper 1999-01-1180, 1999.

3. Antila E, Larmi M, Saarinen A, et al. Cylinder charge, initial flow field and fuel injection boundary condition in the multidimensional modeling of combustion in compression ignition engines. SAE paper 2004-01-2963, 2004.

4. Adomeit P, Pischinger S, Becker M, et al. Potential soot and $\mathrm{CO}$ reduction for HSDI diesel combustion systems. SAE paper 2006-01-1417, 2006.

5. Ge HW, Reitz RD and Willems W. Modeling the effects of in-cylinder flows on HSDI diesel engine performance and emissions. SAE paper 2008-01-0649, 2008.

6. Adolph D, Rezaei R, Pischinger S, et al. Gas exchange optimization and the impact on emission reduction for HSDI diesel engines. SAE paper 2009-01-0653, 2009.

7. Amsden AA. KIVA-3V release 2, improvements to KIVA-3V. Technical report LA-UR-99-915, Los Alamos National Laboratory, 1999.

8. Kong S-C, Han Z and Reitz RD. The development and application of a diesel ignition and combustion model for multidimensional engine simulation. SAE paper 950278, 1995.

9. Launder BE and Spalding DB. The numerical computation of turbulent flows. Comput Methods Appl Mech Eng 1974; 3(2): 269-289.

10. Bardina JE, Huang PG and Coakley TJ. Turbulence modeling validation, testing and development. NASA technical memorandum, 1997.

11. Sone K, Patel N and Menon S. Large-eddy simulation of fuel-air mixing in an internal combustion engine. AIAA paper 2001-0635, 2001.

12. Menon S, Yeung P-K and Kim W-W. Effect of sub-grid models on the computed interscale energy transfer in isotropic turbulence. Comput Fluids 1996; 25(2): 165-180.

13. Sone K, Patel N and Menon S. KIVALES: large-eddy simulations of internal combustion engines. Part I: theory and formulation. Technical Report CCL-2001-008, Georgia Institute of Technology, 2001. 
14. Smagorinsky J. General circulation experiments with the primitive equations I. The basic experiment. Mon Weather Rev 1963; 91(3): 99-164.

15. Von Kuensberg Sarre C, Kong S-C and Reitz RD. Modeling the effects of injector nozzle geometry on diesel sprays. SAE paper 1999-01-0912, 1999.

16. Halstead M, Kirsh L and Quinn C. The autoignition of hydrocarbon fuels at high temperatures and pressures - fitting of a mathematical model. Combust Flame 1977; 30: 45-60.

17. Hiroyasu H and Kadota T. Models for combustion and formation of nitric oxide and soot in DI diesel engines. SAE paper 760129, 1976.

18. Rohs H. Simulation der Emission von Russ und Kohlenmonoxid in Dieselmotoren. PhD Thesis, RWTH Aachen University, Germany, 2006.
19. Kazakov A and Foster DE. Modeling of soot formation during DI diesel combustion using a multi-step phenomenological model. SAE paper 982463, 1998.

20. Backer H, Hopp $M$ and Pungs A. Entwicklung eines Rechenprogramms zur Simulation der dieselmotorischen Russoxidation. Final report FVV-Vorhaben no.: 659, issue 671, 1999.

21. Rezaei R. Numerical investigation of the effect of in-cylinder flow on combustion and emissions of a direct injection diesel engine. PhD Thesis, RWTH Aachen University, Germany, 2011.

22. Ducros F, Nicoud F and Poinsot T. Wall-adapting local eddy-viscosity models for simulations in complex geometries. In: 6th ICFD Conference on Numerical Methods for Fluid Dynamics, 1998, pp. 293-299. 